\title{
Author Correction: Earthquake nucleation and fault slip complexity in the lower crust of central Alaska
}

Carl Tape (D), Stephen Holtkamp (D), Vipul Silwal (D), Jessica Hawthorne (D), Yoshihiro Kaneko (D), Jean Paul Ampuero (D), Chen Ji(D), Natalia Ruppert (D), Kyle Smith (D) and Michael E. West (D)

Correction to: Nature Geoscience https://doi.org/10.1038/s41561-018-0144-2, published online 4 June 2018.

In the version of this Article originally published, the 'Data availability' section contained an incorrect DOI for data from the FLATS (XV) seismic network (https://doi.org/10.7914/SN/ZE_2015); the correct DOI is: https://doi.org/10.7914/SN/XV_2014. This has now been corrected in the online versions.

Published online: 28 June 2018

https://doi.org/10.1038/s41561-018-0183-8

\section{Author Correction: Palaeoclimate constraints on the impact of $2^{\circ} \mathrm{C}$ anthropogenic warming and beyond}

Hubertus Fischer (1), Katrin J. Meissner (1), Alan C. Mix, Nerilie J. Abram (1), Jacqueline Austermann, Victor Brovkin (1), Emilie Capron, Daniele Colombaroli, Anne-Laure Daniau (D), Kelsey A. Dyez, Thomas Felis (D), Sarah A. Finkelstein, Samuel L. Jaccard (D), Erin L. McClymont (1D, Alessio Rovere (1D), Johannes Sutter, Eric W. Wolff(D), Stéphane Affolter, Pepijn Bakker, Juan Antonio Ballesteros-Cánovas, Carlo Barbante, Thibaut Caley, Anders E. Carlson, Olga Churakova (Sidorova), Giuseppe Cortese, Brian F. Cumming, Basil A. S. Davis, Anne de Vernal, Julien Emile-Geay (D), Sherilyn C. Fritz, Paul Gierz, Julia Gottschalk (1D, Max D. Holloway, Fortunat Joos (D), Michal Kucera, Marie-France Loutre, Daniel J. Lunt (1D, Katarzyna Marcisz, Jennifer R. Marlon, Philippe Martinez, Valerie Masson-Delmotte, Christoph Nehrbass-Ahles (D), Bette L. Otto-Bliesner, Christoph C. Raible, Bjørg Risebrobakken, María F. Sánchez Goñi, Jennifer Saleem Arrigo, Michael Sarnthein, Jesper Sjolte (D), Thomas F. Stocker, Patricio A. Velasquez Alvárez, Willy Tinner, Paul J. Valdes, Hendrik Vogel (D), Heinz Wanner, Qing Yan (D), Zicheng Yu (D, Martin Ziegler and Liping Zhou

Correction to: Nature Geoscience https://doi.org/10.1038/s41561-018-0146-0, published online 25 June 2018.

In the version of this Review Article originally published, ref. 10 was mistakenly cited instead of ref. 107 at the end of the sentence: "This complexity of residual ice cover makes it likely that HTM warming was regional, rather than global, and its peak warmth thus had different timing in different locations." In addition, for ref. 108, Scientific Reports was incorrectly given as the publication name; it should have been Scientific Data. These errors have now been corrected in the online versions.

\section{Publisher Correction: Response of Pacific-sector Antarctic ice shelves to the El Niño/Southern Oscillation}

\author{
F. S. Paolo, L. Padman (D), H. A. Fricker, S. Adusumilli, S. Howard and M. R. Siegfried (D)
}

Correction to: Nature Geoscience https://doi.org/10.1038/s41561-017-0033-0, published online 8 January 2018.

In the version of this Article originally published, the word 'from' was incorrectly spelt as 'form' in Fig. 4b-d. In addition, the coloured scale bar was incorrectly labelled with a range of -1.5 to -1.5 ; this should have been -1.5 to +1.5 . These errors have now been corrected in the online versions. 